Check for updates

Cite this: RSC Adv., 2022, 12, 3108

\title{
Structure, preparation and properties of liquid fluoroelastomers with different end groups
}

\author{
Jiayu Duan, ${ }^{a}$ Chen Yang, ${ }^{a}$ Hailan Kang, (D) ab Long Li, ${ }^{\text {ab }}$ Feng Yang, ${ }^{\text {ab }}$ Qinghong Fang, ${ }^{\text {ab }}$ \\ Wenchi $\mathrm{Han}^{\mathrm{ab}}$ and Donghan $\mathrm{Li}$ (iD *ab
}

In order to design and prepare liquid fluoroelastomers with different end groups, and reveal the relationship between the molecular chain structure and properties, we studied on the oxidation degradation method and functional group conversion method to prepare carboxyl-terminated and hydroxyl-terminated liquid fluoroelastomers, respectively. The reaction mechanisms were also deduced. Furthermore, the curing system was created for liquid fluoroelastomers, and systematically analyzed their properties. The sequence type and content of the $-\mathrm{C}=\mathrm{C}$ - and oxygen-containing groups in the samples were measured and characterized by attenuated total reflectance/Fourier transform infrared (ATR-FTIR) spectroscopy, ${ }^{1} \mathrm{H}$ nuclear magnetic resonance $\left({ }^{1} \mathrm{H}-\mathrm{NMR}\right),{ }^{19} \mathrm{~F}-\mathrm{NMR}$ spectroscopy and chemical titration, the molecular weights of liquid fluoroelastomers were measured by gel permeation chromatography (GPC). Differential scanning calorimetry (DSC) and thermogravimetric analysis (TGA) were used to examine the thermal properties, while a viscometer was used to measure the dynamic viscosity of the liquid fluoroelastomers. Then the mechanical and surface properties of the cured samples were examined by universal testing machine and contact angle measurement instrument, respectively. The results show that carboxyl-terminated liquid fluoroelastomer with $2.71 \mathrm{wt} \%$ carboxyl terminal groups can be prepared by oxidation degradation method. When lithium aluminium hydride $\left(\mathrm{LiAlH}_{4}\right)$ was used as the reducing agent, it can efficiently convert carboxyl group to hydroxyl group with a conversion rate of more than $95 \%$. In addition, it can be seen that the dynamic viscosity of the liquid fluoroelastomers were all decreased with the increase of temperature, and it is similar to about $10 \mathrm{~Pa}$ s at $70{ }^{\circ} \mathrm{C}$. Compared with carboxyl-terminated liquid fluoroelastomers, hydroxyl-terminated liquid fluoroelastomers has higher curing reactivity, higher glass transition temperature $\left(T_{\mathrm{g}}\right)$ and thermal decomposition temperature $\left(T_{\mathrm{d}}\right)$, and better mechanical properties of cured samples. The two types of liquid fluoroelastomers with distinct end groups presented distinct hydrophilicity.

Received 22nd October 2021 Accepted 26th December 2021

DOI: $10.1039 / \mathrm{d} 1 \mathrm{ra07810k}$

rsc.li/rsc-advances

\section{Introduction}

Fluoroelastomers are synthetic polymer elastomers containing fluorine atoms on the main-chain or side-chain carbon atoms. ${ }^{1}$ They possess exceptional thermal stability, oil resistance, oxidation resistance and chemical resistance due to the high bond energy (485 $\mathrm{kJ} \mathrm{mol}^{-1}$ ) of the $\mathrm{C}-\mathrm{F}$ bond and the shielding effect of the fluorine atoms on the $-\mathrm{C}=\mathrm{C}$ - bond in its molecular structure. ${ }^{2-5}$ However, they do not fully meet the requirements of modern fluoroelastomer transport devices because of the poor processing performance, complicated processing and complex vulcanisation procedure. ${ }^{6,7}$ As a result, low-molecularweight fluoroelastomers with improved fluidity and plasticity, known as liquid fluoroelastomers, were developed., ${ }^{\mathbf{8} 9}$

${ }^{a}$ College of Materials Science and Engineering, Shenyang University of Chemical Technology, Shenyang 110142, Liaoning, China

${ }^{b}$ Liaoning Provincial Key Laboratory of Rubber \& Elastomer, Shenyang University of Chemical Technology, Shenyang 110142, Liaoning, China
Liquid fluoroelastomers, also known as key materials, has a wide range of potential applications in transportation, medical protection, new energy, national defence and military industries due to their unique properties. They can also be utilised to make fluorine-containing functional polymers, novel battery-sealing materials, raw materials for additive manufacturing (3D printing), high-performance adhesives, caulking agents, coatings and processing complexes.

Liquid fluoroelastomers can be prepared not only by polymerisation methods ${ }^{\mathbf{1 0 , 1 1}}$ but also through oxidation degradation method. ${ }^{12}$ Because the oxidation degradation method is simpler than the polymerisation methods and produces carboxylterminated telechelic polymers in situ, it has attracted wide attention. ${ }^{13}$ Unfortunately, due to their low carboxyl-terminated activity and poor thermal stability, carboxyl-terminated liquid fluoroelastomers are difficult to cure at low temperatures, thus limiting their applicability in particular fields. As a result, carboxyl to hydroxyl group conversion is important for 
enhancing the thermal stability of liquid fluoroelastomers and for lowering the curing temperature.

In organic chemistry, carboxyl group reduction is a crucial process. Since Finholt ${ }^{14}$ discovered the preparation and application of $\mathrm{LiAlH}_{4}$ in 1946, complex metal hydrides have been used as reducing agents in organic synthesis with considerable success. They were swiftly developed and extensively employed, and the number of reagents has gradually expanded in recent years. These reductants exist in the form of complex hydrogen anion salts, which are nucleophiles that can attack the positively charged atoms in unsaturated polar bonds, resulting in a reduction process via hydrogen anion transfer. ${ }^{15,16}$ The carboxyl group can be easily converted to a hydroxyl group simultaneously.

Furthermore, liquid fluoroelastomers themselves have no strength and cannot meet the current research and application requirements, so they must be cured. Epoxy, ${ }^{17,18}$ isocyanate, ${ }^{19}$ aziridine $^{20}$ and carbonised diamines are the most common curing agents used for liquid fluoroelastomers. ${ }^{21}$ Hexamethylene diisocyanate (HDI) is a particularly important aliphatic isocyanate monomer because its molecular chain contains a highly active isocyanate group (-NCO) that can react with active hydrogen groups, such as carboxyl, hydroxyl, amino, carbamate and urea, in the polymer to achieve crosslinking and obtain the desired network structure. ${ }^{22,23}$ Because HDI curing agents do not contain isocyanate groups directly attached to the carbon atoms on the benzene ring, the coatings and adhesives cured by HDI have a series of excellent properties, including weather resistance, chemical reagent resistance, yellowing resistance and powder resistance. ${ }^{24,25}$ The low surface energy of fluoroelastomers has made them popular hydrophobic materials. ${ }^{26,27}$

At present, there are few reports on the preparation methods, reaction mechanism, structure and properties of liquid fluoroelastomers with carboxyl and hydroxyl end groups. Thus, in order to design and prepare liquid fluoroelastomers with different end groups, and reveal the relationship between the molecular chain structure and properties, we studied on the oxidation degradation method and functional group conversion method to prepare carboxyl-terminated and hydroxyl-terminated liquid fluoroelastomers, respectively. The poly(VDF-coHFP) copolymer was chosen as the raw material, the fluoroelastomer formation was confirmed based on the results of spectral analyses and chemical quantification. Furthermore, property tests and comparative analysis of the relationship between the structure and properties of the liquid fluoroelastomers with different end groups were performed.

\section{Experimental details}

\subsection{Materials and chemical agents}

The fluoroelastomer that was made of the copolymer of vinylidene fluoride and hexafluoropropene was purchased from Chenguang Research Institute of Chemical Industry. Carboxylterminated liquid fluoroelastomer was prepared by the oxidation degradation method of the fluoroelastomer. The hydroxylterminated liquid fluoroelastomer was prepared by the functional group conversion method of the carboxyl-terminated liquid fluoroelastomer. Benzyl triethyl ammonium chloride (BTEAC) and $\mathrm{LiAlH}_{4}$ were purchased from Aladdin Industrial Corporation. HDI was purchased from Yantai Wanhua Chemical Group Co., Ltd. Potassium hydroxide (KOH), hydrogen peroxide (30 wt $\left.\% \mathrm{H}_{2} \mathrm{O}_{2}\right)$, hydrochloric acid $(\mathrm{HCl})$, anhydrous ethanol $\left(\mathrm{C}_{2} \mathrm{H}_{5} \mathrm{OH}\right)$ and tetrahydrofuran (THF) were purchased from Tianjin Kemiou Chemical Reagent Co., Ltd.

\subsection{Characterization}

2.2.1 Spectrum analyses. Attenuated total reflectance/ Fourier transform infrared (ATR-FTIR) measurements were performed using the PerkinElmer spectrum one instrument. The FTIR spectra were obtained at the resolution of $4 \mathrm{~cm}^{-1}$ in the range $650-4000 \mathrm{~cm}^{-1}$.

The NMR spectra were recorded on a Bruker AC 80 spectrometer $\left(500 \mathrm{MHz}\right.$ for ${ }^{1} \mathrm{H}, 470 \mathrm{MHz}$ for $\left.{ }^{19} \mathrm{~F}\right)$ at room temperature using acetone- $\mathrm{d}_{6}$ as the solvent and TMS (or $\mathrm{CFCl}_{3}$ ) as the internal standard for the ${ }^{1} \mathrm{H}$ (or $\left.{ }^{19} \mathrm{~F}\right)$ nuclei.

2.2.2 Determination of molecular weight. The molecular weights $\left(M_{\mathrm{n}}\right)$ of the fluoroelastomers were estimated using an integrated gel permeation chromatography (GPC) system (PLGPC50) from A Varian, Inc. Company. PS was employed as the standard, and tetrahydrofuran (HPLC) was used as the mobile phase. The flow rate was $1 \mathrm{~mL} \mathrm{~min}^{-1}$, and the detector temperature was $30^{\circ} \mathrm{C}$.

2.2.3 Chemical titration. The carboxylic functions of the different liquid fluoroelastomers were titrated using a $\mathrm{KOH}-$ $\mathrm{C}_{2} \mathrm{H}_{5} \mathrm{OH}\left(\mathrm{C}=0.05 \mathrm{~mol} \mathrm{~L}^{-1}\right)$ solution according to the China National Standards GB/T 603-2002 and GB/T601-2002.

The carboxyl-terminated or hydroxyl-terminated liquid fluoroelastomer $(m=0.5 \mathrm{~g})$ and THF $(50 \mathrm{~mL})$ were added into an Erlenmeyer flask. Then, phenolphthalein was added $(0.01 \mathrm{~mL})$, and the $-\mathrm{COOH}(\omega)$ content was assessed by the following equation:

$$
\omega=\frac{V \times C \times M_{\mathrm{COOH}}}{m} \times 100 \%
$$

In eqn (1), " $V$ " stands for the volume of the base employed for titration. Furthermore, the conversion rate of the carboxyl group was assessed by the following equation:

$$
\alpha=\frac{\omega_{0}-\omega_{1}}{\omega_{0}} \times 100 \%
$$

In eqn (2), $\omega_{0}$ and $\omega_{1}$ stand for the contents of - $\mathrm{COOH}$ in the carboxyl-terminated liquid fluoroelastomer and the hydroxylterminated liquid fluoroelastomer, respectively.

2.2.4 Thermal properties. The glass transition temperatures of the fluoroelastomers were estimated by Differential Scanning Calorimetry (DSC). The DSC measurements were carried out on a NETZSCH DSC200. The samples were heated from -100 to $+30^{\circ} \mathrm{C}$ at a rate of $5{ }^{\circ} \mathrm{C} \mathrm{min}^{-1}$ to record the curves. The temperature at half-height of the corresponding heat capacity jump was defined as $T_{\mathrm{g}}$. 
The thermal decomposition temperatures of the fluoroelastomers were estimated by thermogravimetry analysis (TGA). The TGA measurements were carried out on a NETZSCH TG209. The samples were heated from $30{ }^{\circ} \mathrm{C}$ to $600{ }^{\circ} \mathrm{C}$ at a rate of $10{ }^{\circ} \mathrm{C} \mathrm{min}^{-1}$ to record the curves.

2.2.5 Dynamic viscosities. The dynamic viscosities of the fluoroelastomers were tested on a DV2T-RV Brookfield viscometer, according to GB/T 2794-2013. The test was carried out in the range of $30-70{ }^{\circ} \mathrm{C}$, and the average value of 3 measurements was calculated for each sample. The absolute viscosity at $50{ }^{\circ} \mathrm{C}$ where it is not stated in the text.

2.2.6 Mechanical properties. Mechanical properties of the fluoroelastomers were estimated by universal testing machine which were carried out on INSTRON 3365. The tensile strength test was carried out in accordance with the national standard GB/T528-82 "Determination of the tensile properties of vulcanized rubber"; the test temperature was $23 \pm 2{ }^{\circ} \mathrm{C}$, and the tensile rate was $500 \mathrm{~mm} \mathrm{~min}^{-1}$; for each group, 5 samples were tested, and the average was calculated. The hardness was tested with an LX-A digital Shore hardness tester.

2.2.7 Surface properties. The surface properties of the fluoroelastomers were estimated by $\mathrm{FM} 40 \mathrm{Mk} 2$ for contact angle measurement instrument. The contact angle was measured on the cured product surfaces with a test water volume of $5 \mu \mathrm{L} ; 5$ different points were selected for each sample tested, and the average value of the 5 points was considered.

\subsection{Preparation}

The carboxyl-terminated liquid fluoroelastomer was prepared by the oxidative degradation of the poly(VDF-co-HFP) copolymer by using an aqueous $\mathrm{KOH}$ solution and $\mathrm{H}_{2} \mathrm{O}_{2}$. The hydroxylterminated liquid fluoroelastomer was prepared by a reductive reaction, in which the carboxyl-terminated liquid fluoroelastomer was reacted with $\mathrm{LiAlH}_{4}$. Then, these products were cured.

2.3.1 Carboxyl-terminated liquid fluoroelastomer. A $2000 \mathrm{~mL}$ flask was filled with the fluoroelastomer $(100 \mathrm{~g})$ and THF $(700 \mathrm{~mL})$. At $10{ }^{\circ} \mathrm{C}$, benzyltriethylammonium chloride (BTEAC, $3 \mathrm{~g}$ ), $30 \mathrm{wt} \% \mathrm{H}_{2} \mathrm{O}_{2}$ aqueous solution and $45 \mathrm{wt} \% \mathrm{KOH}$ aqueous solution were sequentially added to the flask and agitated for $10 \mathrm{~h}$. After the reaction, the organic and inorganic phases were separated; concentrated hydrochloric acid and water were added to the organic phase, and the $\mathrm{pH}$ was corrected to $1-2$. The product was collected and dried to a constant weight at $65-70{ }^{\circ} \mathrm{C}$ in a vacuum drying oven, finally producing a light-yellow viscous liquid.

2.3.2 Hydroxyl-terminated liquid fluoroelastomer. THF $(100 \mathrm{~mL})$ and the carboxyl-terminated liquid fluoroelastomer $(10 \mathrm{~g})$ were added to a $250 \mathrm{~mL}$ flask. $\mathrm{LiAlH}_{4}$ was gently added at room temperature until the fluoropolymer dissolved fully; then, the temperature was elevated to the appropriate value, and the mixture reacted for $3 \mathrm{~h}$. The reaction was then quenched with $20 \mathrm{~mL}$ hydrochloric acid at a concentration of $2.0 \mathrm{~mol} \mathrm{~L}^{-1}$, and the product was rinsed several times with deionised water. Finally, the product was collected and vacuum-dried at $60-65{ }^{\circ} \mathrm{C}$ to a consistent weight, yielding a white viscous liquid.
2.3.3 Curing of the carboxyl-terminated liquid fluoroelastomer with HDI. HDI trimer with a $\mathrm{COOH} / \mathrm{NCO}$ molar ratio of 1.0/1.0-1.0/1.5 was dissolved in acetone $(2 \mathrm{~mL})$, and the carboxyl-terminated liquid fluoroelastomer (10 g) was also dissolved in acetone $(10 \mathrm{~mL})$. To eliminate the solvent, they were evenly mixed and placed in a drying oven set to $60{ }^{\circ} \mathrm{C}$. The solution was poured into a mould that had been preheated to $60{ }^{\circ} \mathrm{C}$ and placed in a vacuum drying box at $60{ }^{\circ} \mathrm{C}$ for $8-48 \mathrm{~h}$ to remove the residual solvent. The temperature was increased to the curing point temperature of $102{ }^{\circ} \mathrm{C}$ after the solvent was removed. A dark yellow cured product was formed after a $6 \mathrm{~h}$ reaction.

2.3.4 Curing of the hydroxyl-terminated liquid fluoroelastomer with HDI trimer. HDI trimer with a $\mathrm{OH} / \mathrm{NCO}$ molar ratio of 1.0/1.0-1.0/1.5 was dissolved in acetone ( $2 \mathrm{~mL}$ ), and hydroxylterminated liquid fluoroelastomer $(10 \mathrm{~g})$ was also dissolved in acetone $(10 \mathrm{~mL})$. To eliminate the solvent, they were evenly mixed and then placed in the drying oven set to $60^{\circ} \mathrm{C}$. When the remaining solvent was about $3-5 \mathrm{~mL}$, the mixture was poured into a mould preheated at $60^{\circ} \mathrm{C}$ and placed in a vacuum drying oven at $60^{\circ} \mathrm{C}$ for $8-48 \mathrm{~h}$ to remove the remaining solvent. After removing the solvent, the temperature was raised to $90{ }^{\circ} \mathrm{C}$, which was the solidification point, and the reaction was carried out for $4 \mathrm{~h}$, yielding a light-yellow solidified product.

\section{Results and discussion}

\subsection{Structure of the liquid fluoroelastomers}

3.1.1 FTIR of the liquid fluoroelastomers. All the FTIR spectra revealed absorption peaks at about $870-890 \mathrm{~cm}^{-1}$, $1155-1180 \mathrm{~cm}^{-1}$ and $1395-1400 \mathrm{~cm}^{-1}$, which could be ascribed to the stretching vibrations of $\mathrm{CF}_{3}, \mathrm{CF}_{2}$ and $\mathrm{CF}$, respectively, as shown in Fig. $1 .^{28}$ There is a new peak belonging to the carboxyl group $\left(-\mathrm{CF}_{2} \mathrm{COOH}\right)$ at $1760-1770 \mathrm{~cm}^{-1}$ of carboxyl-terminated liquid fluoroelastomer (B) indicate that the oxidation degradation method can be used to successfully prepare the carboxylterminated liquid fluoroelastomer. From the characteristic peak of the carboxyl group at 1760-1770 $\mathrm{cm}^{-1}$ weakened significantly with the progress of the reduction reaction and an obvious characteristic hydroxyl peak appeared at 3350$3450 \mathrm{~cm}^{-1}$, demonstrating the noticeable reduction of $-\mathrm{CF}_{2}$ $\mathrm{COOH}$ when $\mathrm{LiAlH}_{4}$ was used.

3.1.2 ${ }^{1}$ H-NMR of liquid fluoroelastomers. As illustrated in Fig. 2, the characteristic structural peaks of the carboxylterminated liquid fluoroelastomer at $\delta=1.55 \mathrm{ppm}, 4.68 \mathrm{ppm}$ and 7.70-7.50 ppm corresponded to $-\mathrm{CF}=\mathrm{C}\left(\mathrm{CF}_{3}\right)-\mathrm{CH}_{2}-,-\left(\mathrm{CF}_{3}\right)$ $\mathrm{C}=\mathrm{CH}-$ and $-\mathrm{CH}=\mathrm{CF}-$, respectively. This demonstrates that the fluoroelastomer underwent an oxidation degradation reaction, with the dehydrofluorination reaction producing the $-\mathrm{C}=$ C- bond under alkaline conditions. ${ }^{29}$

As shown in Fig. 3, compared with the carboxyl-terminated liquid fluoroelastomer, the hydroxyl-terminated liquid fluoroelastomer showed not only the characteristic structural peaks of $-\mathrm{CH}_{2} \mathrm{OH}$ at $\delta=3.63 \mathrm{ppm}$ and $3.75 \mathrm{ppm}$ but also peaks at $\delta=$ $1.55 \mathrm{ppm}, 4.68 \mathrm{ppm}$ and 7.70-7.50 ppm. The corresponding $-\mathrm{C}=\mathrm{C}$ - characteristic structural peaks were significantly weakened, indicating that under the action of $\mathrm{LiAlH}_{4}$, the carboxyl 


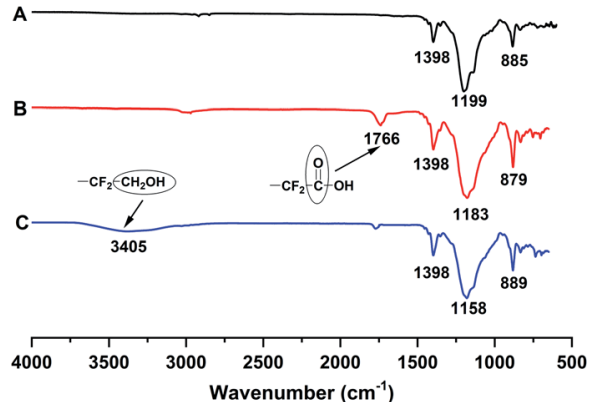

Fig. 1 FTIR spectra of the (A) poly(VDF-co-HFP) copolymer, (B) carboxyl-terminated liquid fluoroelastomer and (C) hydroxyl-terminated liquid fluoroelastomer.

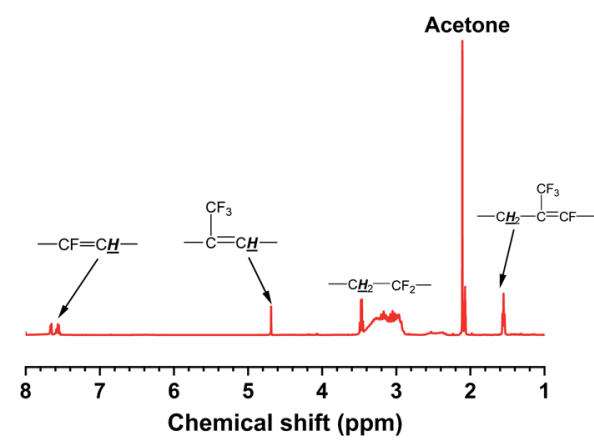

Fig. $2{ }^{1} \mathrm{H}-\mathrm{NMR}$ spectrum of the carboxyl-terminated liquid fluoroelastomer.

groups and $-\mathrm{C}=\mathrm{C}-$ in the carboxyl-terminated liquid fluoroelastomer were all reduced.

3.1.3 ${ }^{19}$ F-NMR of liquid fluoroelastomers. When ${ }^{19} \mathrm{~F}-\mathrm{NMR}$ spectroscopy was used for further characterisation, as shown in Fig. 4 , a peak at $-63.46 \mathrm{ppm}$ ascribed to $-\mathrm{CF}_{2} \mathrm{COOH}$ could be seen. The multiplets at -70 to $76 \mathrm{ppm}$ (b and d), -118 to $120 \mathrm{ppm}(\mathrm{o})$ and -181 to $185 \mathrm{ppm}(\mathrm{p}$ and $\mathrm{q}$ ) were assigned to $-\mathrm{CF}_{3},-\mathrm{CF}_{2}$ - and $-\mathrm{CF}$ - from the HFP sequences, respectively; the multiplets at -91 to $117 \mathrm{ppm}(\mathrm{g}-\mathrm{n})$ were assigned to $-\mathrm{CF}_{2}-$ from the VDF sequences. ${ }^{30-33}$ The detailed attribution is shown in Table 1.

Then, setting $\sum_{1} \mathrm{C}=\mathrm{C}$ as the integral of the $-\mathrm{C}=\mathrm{C}-$ sequences, it was calculated as $\sum_{1} \mathrm{C}=\mathrm{C}=2 / 3\left(I_{-73.71}+I_{-80.66}+\right.$ $\left.I_{-81.30}\right) ; \sum_{1}\left(\mathrm{CF}_{3}+\mathrm{CF}_{2}\right)$ was the integral of the other VDF and HFP sequences, $\sum_{1}\left(\mathrm{CF}_{3}+\mathrm{CF}_{2}\right)=2 / 3\left(I_{-70.67}+I_{-75.19}\right)+I_{-63.46}+$ $I_{-91.62}+I_{-93.56}+I_{-95.64}+I_{-103.62}+I_{-108.96}+I_{-110.51}+I_{-112.53}+$ $I_{-113.95}+I_{-116.24}$. The molar fractions $(\mathrm{mol} \%)$ of $-\mathrm{C}=\mathrm{C}-$ was calculated by the following equation. ${ }^{34}$

$\mathrm{mol} \%$ of $-\mathrm{C}=\mathrm{C}-$ in the copolymer:

$$
X=\frac{\Sigma_{1} \mathrm{C}=\mathrm{C}}{\Sigma_{1} \mathrm{C}=\mathrm{C}+\Sigma_{1}\left(\mathrm{CF}_{3}=\mathrm{CF}_{2}\right)} \times 100 \%
$$

According to the calculations, the molar fractions of $-\mathrm{C}=\mathrm{C}-$ in the carboxyl-terminated and hydroxyl-terminated liquid fluoroelastomers were about $1.12 \mathrm{~mol} \%$ and $0.89 \mathrm{~mol} \%$, respectively.

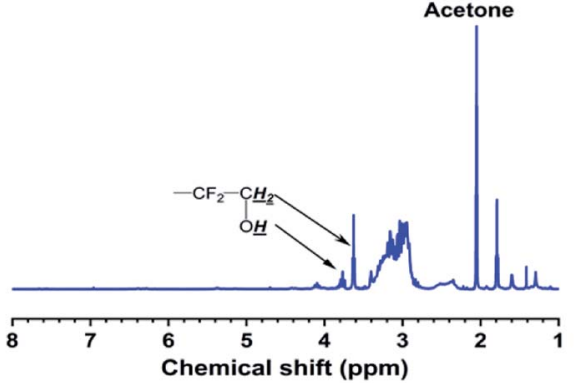

Fig. $3{ }^{1} \mathrm{H}$-NMR spectrum of the hydroxyl-terminated liquid fluoroelastomer.

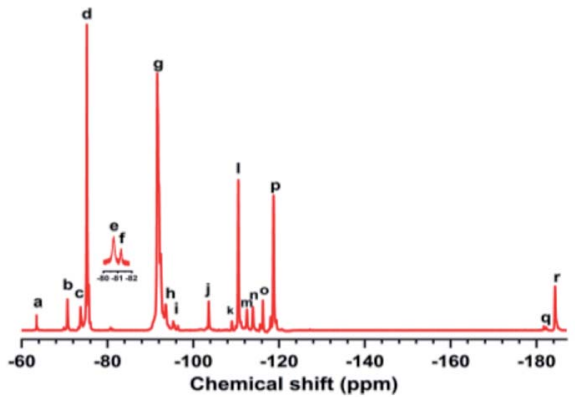

Fig. $4{ }^{19}$ F-NMR spectrum of the carboxyl-terminated liquid fluoroelastomer.

When carboxyl was converted to hydroxyl, not only did the peak assigned to $-\mathrm{CF}_{2} \mathrm{COOH}(\mathrm{a})$ significantly decline and the peaks assigned to $-\mathrm{C}=\mathrm{C}-$ vanish, but the peak centred at $-104.91 \mathrm{ppm}(\mathrm{s})$ belonging to the $-\mathrm{CF}_{2} \mathrm{CH}_{2} \mathrm{OH}$ structure also appeared, as seen in Fig. $5 .^{35}$ As a result, when carboxyl was converted to hydroxyl, the $-\mathrm{C}=\mathrm{C}$ - content decreased as well.

Thus, the successful preparation of the carboxyl-terminated and hydroxyl-terminated liquid fluoroelastomers was confirmed, and the characterisation results matched the FTIR and ${ }^{1} \mathrm{H}-\mathrm{NMR}$ data.

3.1.4 Reaction mechanism. According to the FTIR, ${ }^{1} \mathrm{H}-$ NMR and ${ }^{19} \mathrm{~F}-\mathrm{NMR}$ results, the reaction mechanisms of the formation of carboxyl-terminated and hydroxyl-terminated liquid fluoroelastomers were systematically analysed.

In the alkaline environment of the fluoroelastomer, the hydroxyl ion $\left(\mathrm{OH}^{-}\right)$in $\mathrm{KOH}$ will attack the hydrogen ion $\left(\mathrm{H}^{+}\right)$in the structure of $-\mathrm{CF}_{2} \mathrm{CH}_{2}-$, and a deprotonation reaction occurs, followed by a defluoridation reaction to produce $-\mathrm{C}=\mathrm{C}-$, as illustrated in Scheme 1. Furthermore, when there is a high concentration of alkali or a high temperature in the reaction system, oxygen in the air, the alkali and fluorine continue to interact with $-\mathrm{C}=\mathrm{C}-$, resulting in an oxidation reaction. Subsequently, a hydroxyl group is introduced into the molecular chain, thus resulting in the carboxyl-terminated liquid fluoroelastomer. ${ }^{36,37}$

There are two stages in the reduction of the carboxyl group by $\mathrm{LiAlH}_{4}$. The carboxyl group is reduced to an aldehyde in the first stage. The carboxyl groupis first converted into a carboxylate lithium salt, and then when aluminium hydride $\left(\mathrm{AlH}_{3}\right)$ is 
Table 1 Assignments of the ${ }^{19} \mathrm{~F}-\mathrm{NMR}$ peaks of the carboxyl-terminated liquid fluoroelastomer

\begin{tabular}{|c|c|c|c|c|c|}
\hline No. & $\delta(\mathrm{ppm})$ & Assignment & No. & $\delta(\mathrm{ppm})$ & Assignment \\
\hline a & -63.46 & $-\mathrm{CF}_{2} \mathrm{C}_{2} \mathrm{COOH}$ & $\mathrm{j}$ & -103.62 & $-\mathrm{CF}_{2} \mathrm{CH}_{2} \mathrm{CF}_{2} \mathrm{CF}\left(\mathrm{CF}_{3}\right) \mathrm{CF}_{2}-$ \\
\hline $\mathrm{b}$ & -70.67 & $-\mathrm{CH}_{2} \mathrm{CF}_{2} \mathrm{CF}\left(\mathrm{CF}_{3}\right) \mathrm{CF}_{2} \mathrm{CH}_{2}^{-}$ & $\mathrm{k}$ & -108.96 & $-\mathrm{CF}\left(\mathrm{CF}_{3}\right) \mathrm{CH}_{2} \mathrm{CF}_{2} \mathrm{CF}\left(\mathrm{CF}_{3}\right) \mathrm{CF}_{2}-$ \\
\hline d & -75.19 & $-\mathrm{CF}_{2} \mathrm{CH}_{2} \mathrm{CF}\left(\mathrm{CF}_{3}\right) \mathrm{CF}_{2} \mathrm{CF}_{2}-$ & $\mathrm{m}$ & -112.53 & $-\mathrm{CF}\left(\mathrm{CF}_{3}\right) \mathrm{CH}_{2} \mathrm{CF}_{2} \mathrm{CF}_{2} \mathrm{CH}_{2}-$ \\
\hline e & -80.66 & $-\mathrm{CH}=\mathrm{CFCF}\left(\mathrm{CF}_{3}\right)-$ & $\mathrm{n}$ & -113.95 & $-\mathrm{CF}_{2} \mathrm{CH}_{2} \mathrm{CF}_{2} \mathrm{CF}_{2} \mathrm{CH}_{2}^{-}$ \\
\hline $\mathrm{f}$ & -81.30 & $-\mathrm{CF}=\mathrm{CHCF}\left(\mathrm{C}_{3}\right) \mathrm{CF}_{2^{-}}$ & o & -116.24 & $-\mathrm{CH}_{2} \mathrm{CH}_{2} \underline{\mathrm{CF}}_{2} \mathrm{CF}_{2} \mathrm{CF}\left(\mathrm{CF}_{3}\right)-$ \\
\hline $\mathrm{i}$ & -95.64 & $-\mathrm{CH}_{2} \mathrm{CH}_{2} \mathrm{CF}_{2} \mathrm{CH}_{2} \mathrm{CF}_{2}-$ & $\mathrm{r}$ & -184.33 & $-\mathrm{CF}_{2} \mathrm{CF}_{2} \mathrm{C} \underline{\boldsymbol{F}}\left(\mathrm{CF}_{3}\right) \mathrm{CH}_{2} \mathrm{CF}_{2}-$ \\
\hline
\end{tabular}

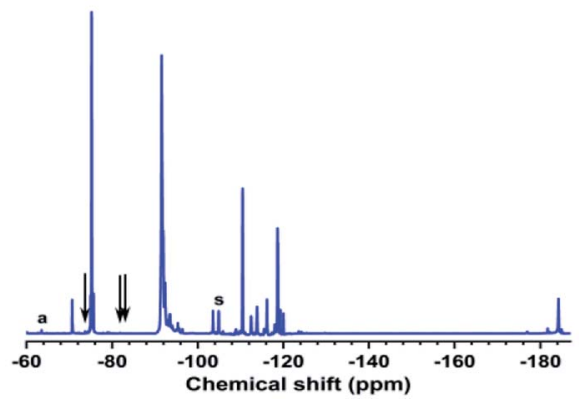

Fig. $5{ }^{19} \mathrm{~F}-\mathrm{NMR}$ spectrum of the hydroxyl-terminated liquid fluoroelastomer.

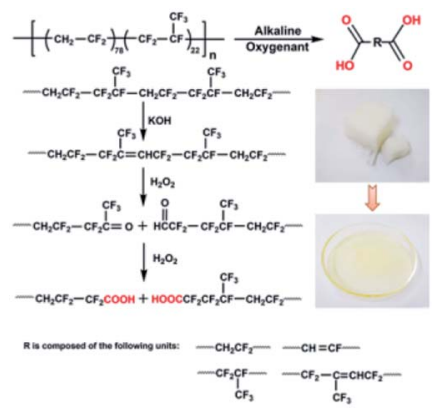

Scheme 1 Mechanism of the oxidation degradation method.

close by, it forms a complex with the carbonyl oxygen. Then, to convert $\mathrm{LiOAlH}_{2}$ to formaldehyde, the negative hydrogen from aluminium is transferred to the carbonyl carbon. The aldehyde
Table 2 End-group content in the liquid fluoroelastomers

\begin{tabular}{lll}
\hline End group & COOH $(w t \%)$ & Conversion ratio (\%) \\
\hline Carboxyl & 2.71 & - \\
Hydroxyl & 0.12 & 95.57 \\
\hline
\end{tabular}

combines with a second molecule of lithium aluminium hydride in the second step. $\mathrm{AlH}_{4}{ }^{-}$, being the lone offensive reagent, forms alkoxides by transferring a hydride ion to the carbon via a quaternary cyclic transition state, and these are then hydrolysed to obtain alcohols. ${ }^{38}$

The above spectral test results show that unlike hydrocarbons or polymers, when $\mathrm{LiAlH}_{4}$ was utilised as the reducing agent in a fluorine-containing system, the carboxyl group was reduced, while only a portion of the $-\mathrm{C}=\mathrm{C}$ - was reduced. The reaction mechanism is shown in Scheme 2; the electron cloud density is high due to the weak polarity of $-\mathrm{C}=\mathrm{C}-$, which makes it a difficult target for attack by nucleophiles $\left(\mathrm{AlH}_{4}{ }^{-}\right)$, and the electronegativity of the fluorine atom is relatively large, which causes the electron cloud density to shift and reduce, allowing nucleophiles to attack it. The hydride ions are then transferred to positively charged carbon atoms to form complexes, which combine with protons to complete the hydrogenation reduction process. $^{39}$

The end-group concentration in the carboxyl-terminated and hydroxyl-terminated liquid fluoroelastomers was then determined, and the conversion rate in the reduction reaction was nearly 96\%. The results are shown in Table 2.

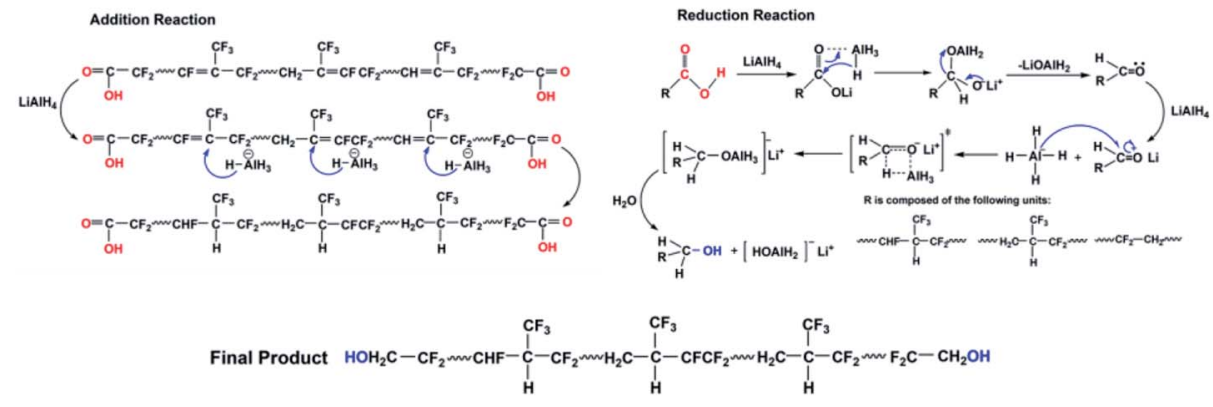

Scheme 2 Reaction mechanism of the reduction reaction and double bond addition. 


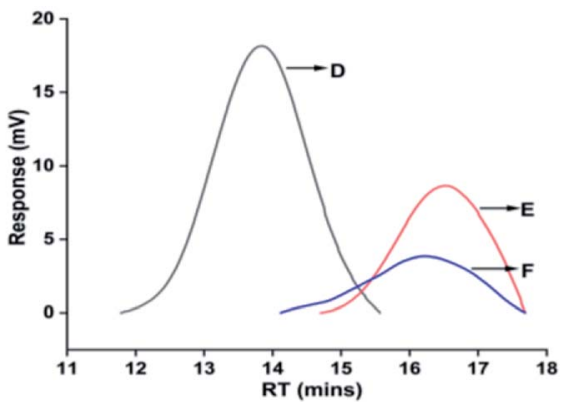

Fig. 6 GPC spectra of the (D) poly(VDF-co-HFP) copolymer, (E) carboxyl-terminated liquid fluoroelastomer and (F) hydroxyl-terminated liquid fluoroelastomer.

Table 3 Assignments of GPC in liquid fluoroelastomers

\begin{tabular}{|c|c|c|c|}
\hline Sample & $M_{\mathrm{n}}$ & $M_{\mathrm{w}}$ & $\mathrm{PD}$ \\
\hline Poly(VDF-co-HFP) copolymer & 71724 & 157904 & 2.20 \\
\hline $\begin{array}{l}\text { Carboxy-terminated } \\
\text { fluoroelastomer }\end{array}$ & 2458 & 4788 & 1.95 \\
\hline $\begin{array}{l}\text { Hydroxy-terminated } \\
\text { fluoroelastomer }\end{array}$ & 2680 & 6904 & 2.57 \\
\hline
\end{tabular}

3.1.5 GPC of the liquid fluoroelastomers. As demonstrated in Fig. 6, the $M_{\mathrm{n}}$ of the carboxyl-terminated liquid fluoroelastomer prepared by the oxidation degradation reaction was significantly low; however, when carboxyl was converted to hydroxyl, the $M_{\mathrm{n}}$ of the hydroxyl-terminated liquid fluoroelastomer increased, which is due to the simultaneous addition reaction at the $-\mathrm{C}=\mathrm{C}$ - groups in the molecular chain along with the reduction reaction. The detailed values are shown in Table 3.

\subsection{Thermal properties of the liquid fluoroelastomers}

3.2.1 Low-temperature property. The cohesive energy density of the fluoroelastomers was higher than those of other polymers due to the strong nature of their structural chemistry and strong polarity; hence, their low-temperature properties were not optimum. ${ }^{\mathbf{4 0 , 4 1}}$ Meanwhile, the $T_{\mathrm{g}}$ of the raw material characterises the elastic capabilities of the product under lowtemperature settings and reflects the thermal motion ability

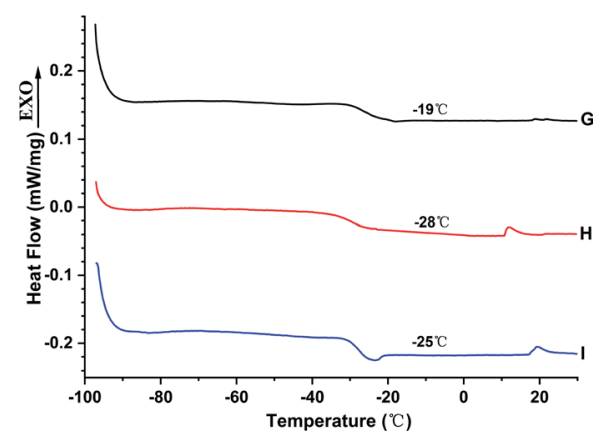

Fig. 7 DSC of the (G) poly(VDF-co-HFP) copolymer, $(\mathrm{H})$ carboxylterminated liquid fluoroelastomer and (I) hydroxyl-terminated liquid fluoroelastomer. of the macromolecular chains. DSC was used to study and analyse the $T_{\mathrm{g}}$ of the raw materials and the liquid fluoroelastomers.

The $T_{\mathrm{g}}$ of the liquid fluoroelastomers generated from the poly(VDF-co-HFP) copolymer fell dramatically from $-19{ }^{\circ} \mathrm{C}$ to $-25{ }^{\circ} \mathrm{C}$, as illustrated in Fig. 7 , with a temperature difference of about $-6{ }^{\circ} \mathrm{C}$ to $-9{ }^{\circ} \mathrm{C}$. Due to the presence of isolated $-\mathrm{C}=\mathrm{C}$ - in the molecular chain, the carboxyl-terminated liquid fluoroelastomer generated by the oxidation degradation method showed increased flexibility of the molecular chain, resulting in a drop in $T_{\mathrm{g}}$. The $T_{\mathrm{g}}$ of the hydroxyl-terminated liquid fluoroelastomer increased from $-28{ }^{\circ} \mathrm{C}$ to $-25{ }^{\circ} \mathrm{C}$ after the reduction reaction, and the temperature contrast was $-3{ }^{\circ} \mathrm{C}$; the $-\mathrm{C}=$ $\mathrm{C}-$ in the molecular chain were reduced to single bonds. As a result, the number of isolated double bonds in the chain were reduced, limiting molecular chain flexibility and raising the $T_{\mathrm{g}}$. The reason for this, based on the ${ }^{19}$ F-NMR results in Fig. 4 and 5 , is the addition of hydrogen atoms to $-\mathrm{C}=\mathrm{C}$ - during the reduction reaction, which would improve the tacticity of the molecular chains. ${ }^{\mathbf{4 2 , 4 3}}$ The presence of $-\mathrm{C}=\mathrm{C}$ - in the molecular chains thus had a significant impact on the low-temperature property.

3.2.2 High-temperature stability. The $T_{\mathrm{d}}$ of the liquid fluoroelastomers is critical because the heat resistance of the raw material controls the heat resistance of the product. ${ }^{44}$ In addition, we compared the raw materials with the liquid fluoroelastomers.

The TGA studies showed that the $T_{\mathrm{d}}$ of the liquid fluoroelastomers generated using the poly(VDF-co-HFP) copolymer fell dramatically from $442{ }^{\circ} \mathrm{C}$ to $235{ }^{\circ} \mathrm{C}$, as shown in Fig. 8. It was found that contents of carboxyl and $-\mathrm{C}=\mathrm{C}-$ were the root causes of this phenomenon. The $-\mathrm{C}=\mathrm{C}-$ in the molecular chain were reduced to single bonds, and the content of isolated double bonds in the chain decreased, thereby limiting molecular chain flexibility and increasing the $T_{\mathrm{d}}$. As a result, the $T_{\mathrm{d}}$ of the hydroxyl-terminated liquid fluoroelastomer was enhanced from $235{ }^{\circ} \mathrm{C}$ to $241{ }^{\circ} \mathrm{C}$, according to TGA results. Hence, the content of $-\mathrm{C}=\mathrm{C}-$ had a significant impact on the $T_{\mathrm{d}}$. Nevertheless, the TGA results showed that the material was stable and that no chemicals/residues could alter its thermal properties.

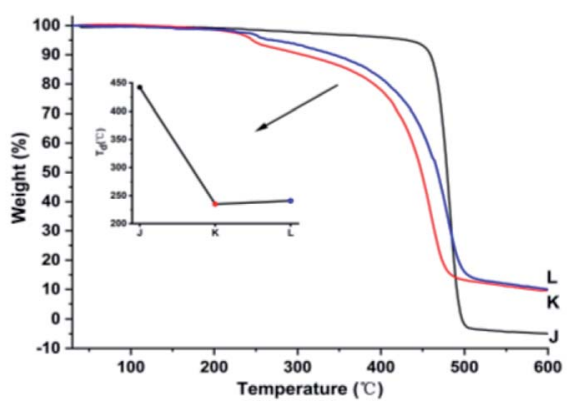

Fig. 8 TGA of the (J) poly(VDF-co-HFP) copolymer, (K) carboxylterminated liquid fluoroelastomer and $(L)$ hydroxyl-terminated liquid fluoroelastomer. 


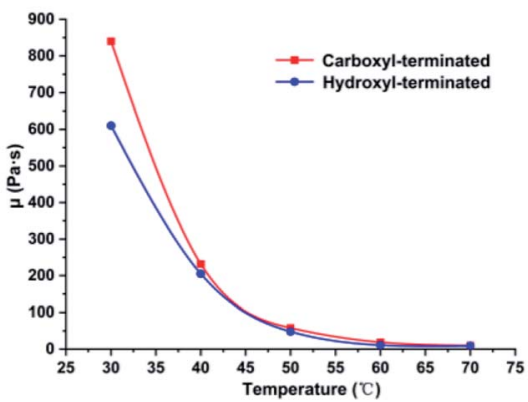

Fig. 9 Dynamic viscosities of the carboxyl-terminated liquid fluoroelastomer and the hydroxyl-terminated liquid fluoroelastomer.

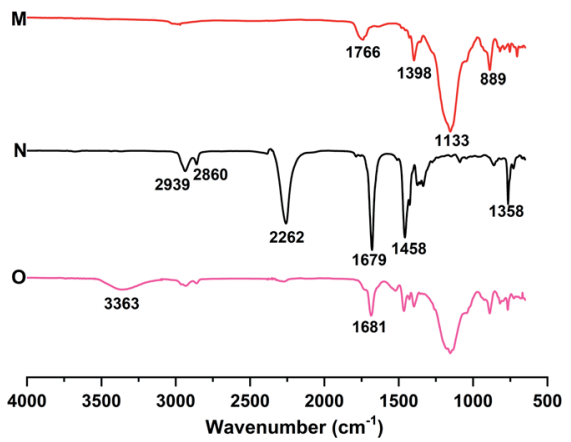

Fig. 10 FTIR spectra of the (M) carboxyl-terminated liquid fluoroelastomer, $(\mathrm{N}) \mathrm{HDI}$ trimer and $(\mathrm{O})$ cured fluoroelastomer

\subsection{Dynamic viscosities of the liquid fluoroelastomers}

At $30-70{ }^{\circ} \mathrm{C}$, the dynamic viscosity of the liquid fluoroelastomers with carboxyl-terminated and hydroxyl-terminated chains was measured, and the findings are presented in Fig. 9.

The dynamic viscosity of the hydroxyl-terminated liquid fluoroelastomer was lower than that of the carboxyl-terminated liquid fluoroelastomer at $30-50{ }^{\circ} \mathrm{C}$, as shown in Fig. 9. Because the carboxyl group has stronger polarity than the hydroxyl group, the intermolecular force of a carboxyl-terminated liquid fluoroelastomer is larger, resulting in higher dynamic viscosity. The dynamic viscosity of the hydroxyl-terminated liquid fluoroelastomer was $48 \mathrm{~Pa} \mathrm{~s}$ at $50{ }^{\circ} \mathrm{C}$, which was lower than the dynamic viscosity of carboxyl-terminated liquid fluoroelastomer, which was $58 \mathrm{~Pa}$ s. When the test temperature exceeded $50{ }^{\circ} \mathrm{C}$, the dynamic viscosities of them are both decreases and tends to equalise, around $10 \mathrm{~Pa} \mathrm{~s}$, and the end group effect on the dynamic viscosity of the liquid fluoroelastomer disappeared.

\subsection{Curing of the liquid fluoroelastomers}

At room temperature, the liquid fluoroelastomers were viscous liquids or semi-solids with no strength. Thus, they had to be cured before use as curing might impart outstanding mechanical properties, excellent thermal stability, and chemical stability. Therefore, the liquid fluoroelastomers were cured, and the structures of the cured products, as well as the influence of heat and the amount of curing agent on the mechanical and

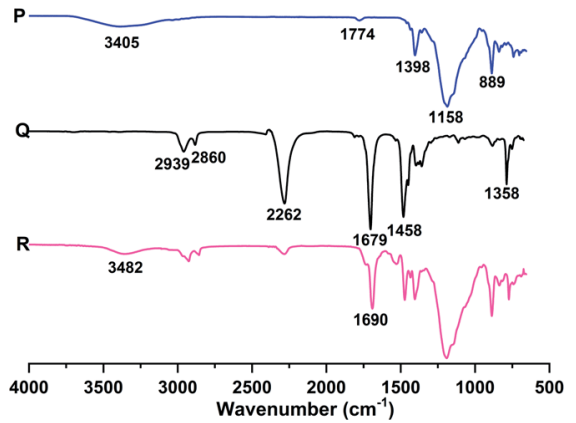

Fig. 11 FTIR spectra of the (P) hydroxyl-terminated liquid fluoroelastomer, (Q) HDI trimer and (R) cured fluoroelastomer.

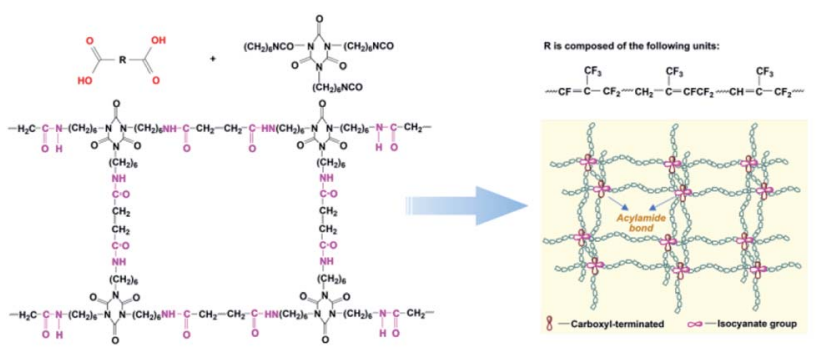

Scheme 3 Mechanism of curing of the carboxyl-terminated liquid fluoroelastomer.

surface properties of the cured products, were investigated and analysed.

3.4.1 Structure of the cured liquid fluoroelastomers. In the FTIR spectrum, HDI (curve N) presented a stretching vibration peak and an opposite stretching vibration peak corresponding to the $\mathrm{C}-\mathrm{H}$ at $2939 \mathrm{~cm}^{-1}$ and $2860 \mathrm{~cm}^{-1}$, respectively, and an opposite stretching vibration peak corresponding to the $-\mathrm{NCO}$ at $2262 \mathrm{~cm}^{-1}$, as illustrated in Fig. 10. The $-\mathrm{NCO}$ of the urea bond produced a stretching vibration peak at $1679 \mathrm{~cm}^{-1}$, while the isocyanurate ring generated a stretching vibration peak at $1458 \mathrm{~cm}^{-1}$. The cured carboxyl-terminated product (curve O) featured a new stretching vibration peak of $\mathrm{N}-\mathrm{H}$ at $3363 \mathrm{~cm}^{-1}$, strongly corresponding with the peak of the $\mathrm{C}=\mathrm{O}$ at $1681 \mathrm{~cm}^{-1}$. Thus, these demonstrated that HDI could cure the carboxylterminated liquid fluoroelastomer.
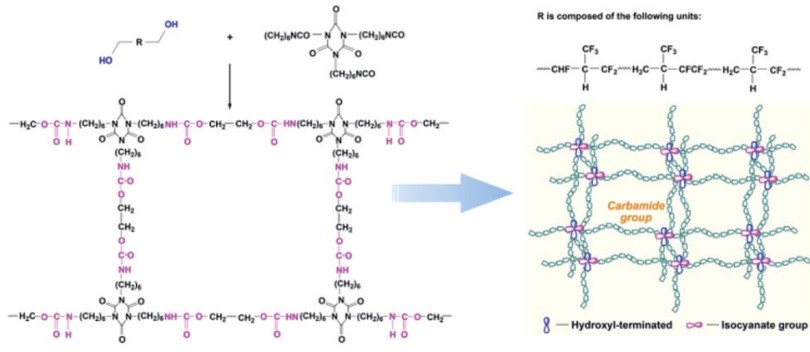

Scheme 4 Mechanism of curing of the hydroxyl-terminated liquid fluoroelastomers. 


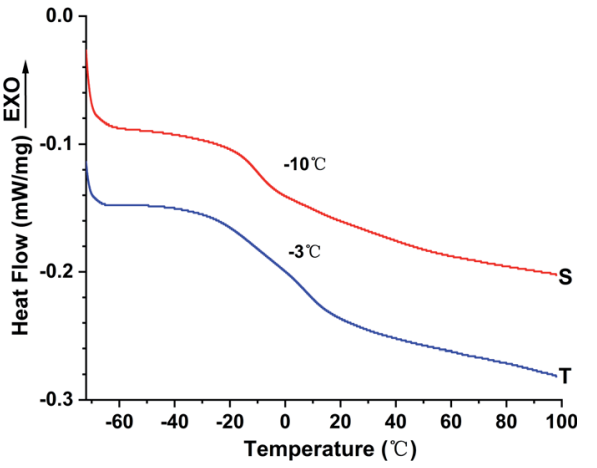

Fig. 12 DSC of the cured products of the (S) carboxyl-terminated liquid fluoroelastomer and (T) hydroxyl-terminated liquid fluoroelastomer.

As illustrated in Fig. 11, the characteristic peak of the hydroxyl group at $3405 \mathrm{~cm}^{-1}$ weakened significantly with the progress of the curing reaction, and the stretching vibration peaks corresponding to the $\mathrm{N}-\mathrm{H}$ and $\mathrm{C}=\mathrm{O}$ in the carbamide groups (-NHCOO-) structure appeared at $3482 \mathrm{~cm}^{-1}$ and $1690 \mathrm{~cm}^{-1}$, respectively. Thus, HDI was shown to cure the hydroxyl-terminated liquid fluoroelastomer.

3.4.2 Mechanism of curing of the liquid fluoroelastomers. Because of its highly unsaturated structure, the -NCO is highly reactive. ${ }^{45}$ The isocyanate and carboxyl groups produce carboxyl anhydride with poor thermal stability during the curing procedure; it is then decomposed by heat to produce amide bonds and carbon dioxide, thus curing the carboxyl-terminated liquid fluoroelastomer, as shown in Scheme 3.

The $-\mathrm{CH}_{2} \mathrm{OH}$ of the hydroxyl-terminated liquid fluoroelastomer comprises a nucleophilic active hydrogen group containing oxygen atoms, which attacks the -NCO carbon atoms, as indicated in Scheme 4. Meanwhile, because the carbonnitrogen double bond has low bond energy, the active hydrogen may easily interact with the nitrogen atoms in -NCO and create stable -NHCOOH-, allowing the hydroxyl-terminated liquid fluoroelastomer to be cured.

3.4.3 Low-temperature property of the cured liquid fluoroelastomers. The $T_{\mathrm{g}}$ of the cured carboxyl-terminated and hydroxyl-terminated liquid fluoroelastomers dramatically

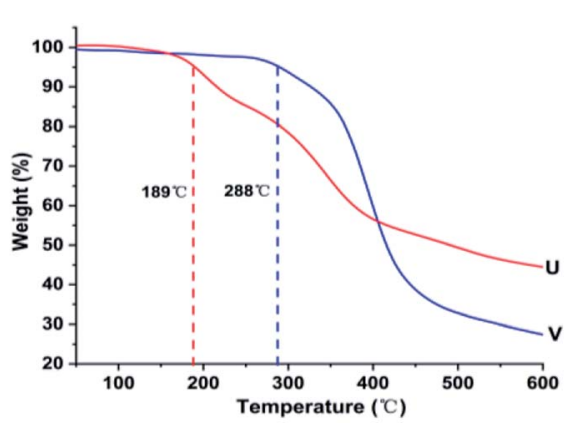

Fig. 13 TGA of the cured products of the $(U)$ carboxyl-terminated liquid fluoroelastomer and (V) hydroxyl-terminated liquid fluoroelastomer. enhanced to $-10{ }^{\circ} \mathrm{C}$ and $-3{ }^{\circ} \mathrm{C}$, respectively, as illustrated in Fig. 12. The molecular chain formed networks after curing, thus reducing the flexibility of the molecular chain of the liquid fluoroelastomer and raising the $T_{\mathrm{g}}$. Because the hydroxylterminated liquid fluoroelastomer had a lower $-\mathrm{C}=\mathrm{C}-$ content than the carboxyl-terminated liquid fluoroelastomer, its $T_{\mathrm{g}}$ was higher than that of the carboxyl-terminated liquid fluoroelastomer.

3.4.4 High-temperature stability of the cured liquid fluoroelastomers. The $T_{\mathrm{d}}$ of the cured carboxyl-terminated and hydroxyl-terminated liquid fluoroelastomers were $189{ }^{\circ} \mathrm{C}$ and $288{ }^{\circ} \mathrm{C}$, respectively, as illustrated in Fig. 13. It is obvious that after the curing reaction, $T_{\mathrm{d}}$ shows an upward trend. Because of the low content of $-\mathrm{C}=\mathrm{C}-$ in the molecular chains of the liquid fluoroelastomers with different end groups, the molecular weight increased after curing, and the molecular chains formed a network structure, which reduced the flexibility of the liquid fluoroelastomer molecular chains, thus increasing their $T_{\mathrm{d}}$. Because the hydroxyl-terminated liquid fluoroelastomer had lesser $-\mathrm{C}=\mathrm{C}$ - content than the carboxyl-terminated liquid fluoroelastomer, its $T_{\mathrm{d}}$ was higher than that of the carboxylterminated liquid fluoroelastomer.

3.4.5 Mechanical properties of the cured liquid fluoroelastomers. Fig. 14 shows the influence of HDI content on the mechanical properties of the carboxyl-terminated liquid fluoroelastomers at constant curing conditions.

The tensile strength of the carboxyl-terminated liquid fluoroelastomers after curing improved as the HDI proportion increased, and the elongation at break point decreased, as illustrated in Fig. 14. When the $\mathrm{COOH} / \mathrm{NCO}$ molar ratio was 1.0/ 1.0 , the tensile strength of the cured product was only $0.48 \mathrm{MPa}$, and the elongation at break was $198 \%$; when the $\mathrm{COOH} / \mathrm{NCO}$ molar ratio was $1.0 / 1.2$, the tensile strength was $1.23 \mathrm{MPa}$, and the elongation at break was $125 \%$; when the $\mathrm{COOH} / \mathrm{NCO}$ molar ratio was further increased to $1.0 / 1.5$, the tensile strength of the cured product increased to $2.26 \mathrm{MPa}$, and the elongation at break was the least at $73 \%$. Because the crosslinking density in the cured product increases as the curing agents are increased, the mechanical properties of the cured product were also enhanced.

The tensile strength of the cured hydroxyl-terminated liquid fluoroelastomer increased when the amount of HDI trimer was

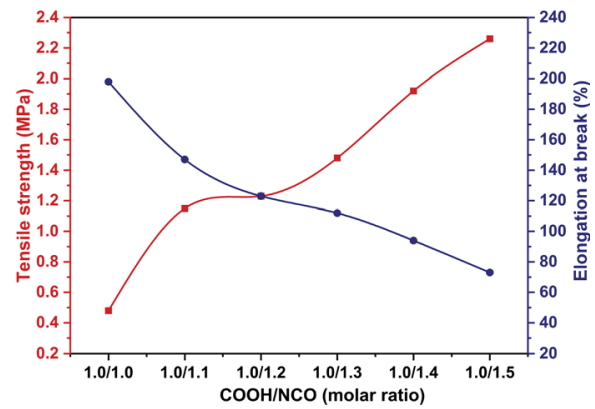

Fig. 14 Effect of HDI content on the mechanical properties of the cured carboxyl-terminated liquid fluoroelastomer. 


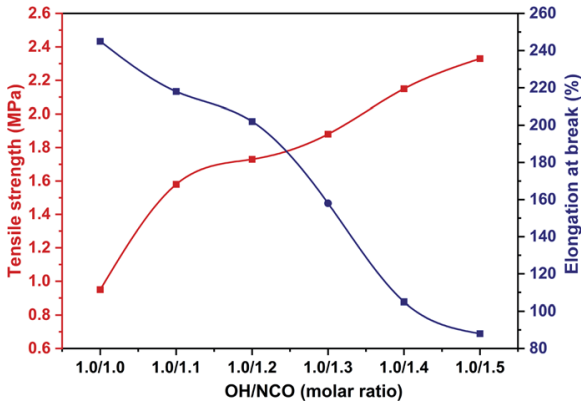

Fig. 15 Effect of HDI content on the mechanical properties of the cured hydroxyl-terminated liquid fluoroelastomer.

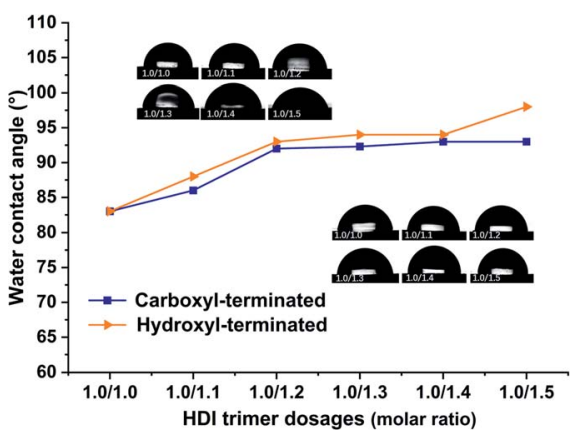

Fig. 16 Effect of HDI content on the surface properties of the cured carboxyl-terminated and hydroxyl-terminated liquid fluoroelastomers.

increased, and the elongation at break decreased, as shown in Fig. 15. The compressive mechanical properties of the cured product were higher when the $\mathrm{OH} / \mathrm{NCO}$ molar ratio was 1.0/1.2, with a tensile strength of $1.73 \mathrm{MPa}$ and $202 \%$ elongation at break. The tensile strength of the cured product was as high as $2.33 \mathrm{MPa}$ when the $\mathrm{COOH} / \mathrm{NCO}$ molar ratio was $1.0 / 1.5$, and the elongation at break was the least at $88 \%$. The mechanical properties of the cured hydroxyl-terminated liquid fluoroelastomer product were superior to those of the HDI-cured carboxylterminated liquid fluoroelastomer (Fig. 14). The reaction temperature was lower and the reaction time was shorter when the hydroxyl-terminated liquid fluoroelastomer was cured with HDI, preventing thermal oxygen agentisation of the liquid fluoroelastomers and oxidation degradation of the molecular chains. Further, there was no formation of small molecule products during the reaction, and there were no internal defects and holes in the cured product, which was also one of the reasons.

3.4.6 Surface properties of the cured liquid fluoroelastomers. The water contact angle of the cured carboxylterminated and hydroxyl-terminated liquid fluoroelastomers increased with the curing agent content, as illustrated in Fig. 16. The WCA tended to be stable at $93^{\circ}$ and $94^{\circ}$ when the ratio of the carboxyl-terminated and hydroxyl-terminated liquid fluoroelastomers to the curing agent was 1/1.4. The WCA reached its maxima at $93^{\circ}$ and $98^{\circ}$, respectively, when the ratio of carboxylterminated and hydroxyl-terminated liquid fluoroelastomers to
Table 4 Effect of HDI content on the WCA

\begin{tabular}{lllllll}
\hline End group & $1 / 1.0$ & $1 / 1.1$ & $1 / 1.2$ & $1 / 1.3$ & $1 / 1.4$ & $1 / 1.5$ \\
\hline Carboxyl-terminated & $89^{\circ}$ & $86^{\circ}$ & $92^{\circ}$ & $92^{\circ}$ & $93^{\circ}$ & $93^{\circ}$ \\
Hydroxyl-terminated & $83^{\circ}$ & $88^{\circ}$ & $93^{\circ}$ & $94^{\circ}$ & $94^{\circ}$ & $98^{\circ}$
\end{tabular}

the curing agent was $1 / 1.5$, and the hydrophilicity of the hydroxyl-terminated liquid fluoroelastomer was higher than that of the carboxyl-terminated liquid fluoroelastomer. The surface energy of the carboxyl-terminated and hydroxylterminated liquid fluoroelastomers decreased as the curing agent content increased, and a hydrophobic structure forms on the surface of the samples.

Furthermore, the hydroxyl-terminated liquid fluoroelastomer was more compatible with the curing agent than the carboxyl-terminated liquid fluoroelastomer. The range of surface energy loss was greater, and the samples were hydrophobic. ${ }^{46,47}$ The detailed results are shown in Table 4.

\section{Conclusions}

In summary, the molecular weight of the poly(VDF-co-HFP) copolymer reduced dramatically after the oxidation degradation reaction from 71724 to 2458 , so carboxyl-terminated liquid fluoroelastomer with $2.71 \mathrm{wt} \%$ carboxyl terminal groups can be prepared by oxidation degradation method, and there are about $1.12 \mathrm{~mol} \%-\mathrm{C}=\mathrm{C}-$ in the chains of carboxyl-terminated liquid fluoroelastomer were not completely been oxidative degraded. After reduction reaction, the concent of carboxyl group of carboxyl-terminated liquid fluoroelastomer was reduced to $0.12 \mathrm{wt} \%$, with the end-group conversion rate about $96 \%$. At the same time, the $-\mathrm{C}=\mathrm{C}-$ content was also been reduced. The $M_{\mathrm{n}}$ of the hydroxyl-terminated liquid fluoroelastomer increased to 2680 as a result of the hydrogen-addition reaction in the molecular chain.

Furthermore, the molecular weight and $-\mathrm{C}=\mathrm{C}$ - concentration had a direct impact on the carboxyl-terminated and hydroxyl-terminated liquid fluoroelastomers properties. The lower the molecular weight and the greater the $-\mathrm{C}=\mathrm{C}-$ concentration, the lower was the temperature resistance. Similarly, the lower the $-\mathrm{C}=\mathrm{C}-$ concentration and the higher the molecular weight, the better was the thermal stability. The $T_{\mathrm{g}}$ of the carboxyl-terminated liquid fluoroelastomer was $-28{ }^{\circ} \mathrm{C}$, which was $3{ }^{\circ} \mathrm{C}$ lower than that of the hydroxyl-terminated liquid fluoroelastomer, whereas the $T_{\mathrm{d}}$ of the hydroxyl counterpart was higher by $6{ }^{\circ} \mathrm{C}$ at $241{ }^{\circ} \mathrm{C}$. The dynamic viscosity of the liquid fluoroelastomers with different end groups were all decreased with the increase of temperature and similar to about 10 Pa s at $70{ }^{\circ} \mathrm{C}$.

After curing, the different end groups of the liquid fluoroelastomers presented distinct curing efficiency and properties. Because the activity of the hydroxyl group is higher than that of the carboxyl group, it could be cured efficiently in a shorter time. The $T_{d}$ of the cured hydroxyl-terminated liquid 
fluoroelastomer reached $288^{\circ} \mathrm{C}$, which was about $100{ }^{\circ} \mathrm{C}$ higher than that of the cured carboxyl-terminated liquid fluoroelastomer. However, its low-temperature resistance property was poorer, with a $T_{\mathrm{g}}$ of $-3{ }^{\circ} \mathrm{C}$ compared with $-10{ }^{\circ} \mathrm{C}$ of its carboxyl counterpart. The tensile strength was $2.33 \mathrm{MPa}$ and the elongation at break was $88 \%$. In addition, they are both exhibited hydrophilic behaviour, the WCA of the hydroxyl-terminated liquid fluoroelastomer was $98^{\circ}$. And the higher the activity of the end group, the stronger was the hydrophilicity.

\section{Conflicts of interest}

The authors declare no competing financial interests.

\section{Acknowledgements}

The authors are grateful for the National Natural Science Foundation Youth Fund of China (contract grant numbers 52003165), the Doctoral Scientific Research Foundation of Liaoning Province (contract grant numbers 2019-BS-190), the Program for Young \& Middle-aged Scientific and Technological Innovative Talents of Shenyang (contract grant number RC210195), the Educational Department Foundation of Liaoning Province (contract grant numbers LQ2019005), and the Program for Liaoning Innovative Talents in Universities of China (contract grant numbers LR2019053).

\section{References}

1 P. Ferrandez, Fluoroelastomers, FKM and FEPM, in Handbook of Specialty Elastomers, ed. C. K. Robert, Taylor \& Francis Group, New York, 2008, pp. 133-154.

2 M. I. Abdelhamid, A. M. Aboelwafa, H. Elhadidy and A. Habib, Int. J. Polym. Mater. Polym. Biomater., 2012, 61, 505-519.

3 B. Ameduri, B. Boutevin and G. Kostov, Prog. Polym. Sci., 2001, 26, 105-187.

4 J. Li, Y. F. Lu, Y. Liu, Y. Li, X. A. Zhang and S. C. Qi, Polym.Plast. Technol. Eng., 2014, 53, 46-53.

5 B. Ameduri, Macromolecules, 2010, 43, 10163-10184.

6 M. Destarac, K. Matyjaszewski, E. Silverman, B. Ameduri and B. Boutevin, Macromolecules, 2000, 33, 4613-4615.

7 B. Ameduri, Chem. Rev., 2019, 109, 6632-6686.

8 R. Saint-Loup and B. Ameduri, J. Fluorine Chem., 2002, 116, 27-34.

9 S. Mitra, A. Ghanbari-Siahkali, P. Kingshott, S. Hvilsted and K. Almdal, J. Polym. Sci., Part A: Polym. Chem., 2010, 42, 62166229.

10 A. Zaggia and B. Ameduri, Curr. Opin. Colloid Interface Sci., 2012, 17, 188-195.

11 M. A. Tasdelen, M. U. Kahveci and Y. Yagci, Prog. Polym. Sci., 2011, 36, 455-567.

12 Y. F. Chang, M. Y. Liao and X. Y. Li, $R S C A d v ., 2020,10$, 10932-10938.

13 Q. Yu, Handbook of Rubber Raw Materials, Chemical Industry Press, Beijing, 2nd edn, 2007.
14 A. E. Finholt, A. C. jun Bond and H. I. Schlesinger, J. Am. Chem. Soc., 1947, 69, 1199-1203.

15 J. Wang, M. Y. Ju, X. H. Wang, Y. N. Ma, D. H. Wei and X. N. Chen, J. Org. Chem., 2021, 86, 5305-5316.

16 B. Thiedemann, C. M. L. Schmitz and A. Staubitz, J. Org. Chem., 2014, 79, 10284-10295.

17 L. Calabrese and A. Valenza, Eur. Polym. J., 2003, 39, 13551363.

18 C. W. Wise, W. D. Cook and A. A. Goodwin, Polym, 2000, 41, 4625-4633.

19 K. K. Chen, S. Yuan, X. M. Wen, C. Sang and Y. J. Luo, Propellants, Explos., Pyrotech., 2021, 46, 428-439.

20 L. Sauguet, B. Ameduri and B. Boutevin, J. Polym. Sci., Part A: Polym. Chem., 2006, 44, 4566-4578.

21 L. C. J Hesselmans, A. J. Derlken and J. A. M. van den Goorbergh, Prog. Org. Coat., 2006, 55, 142-148.

22 Y. Ebrahimabadi, M. Mehrshad, M. Mokhtar and M. Abdollahi, J. Appl. Polym. Sci., 2021, 138, 49932.

23 N. Wingborg, Polym. Test., 2002, 21, 283-287.

24 J. G. Kennemur and B. M. Novak, Polymer, 2011, 52, 16931710.

25 X. D. Zheng, S. J. Qiu, L. M. Feng, M. T. Wang, H. L. Li, X. X. Gen and Z. Z. Zhang, Polym. Bull., 2006, 56, 563-569.

26 D. Kitaga and S. Kobatake, Chem. Sci., 2012, 3, 1445-1449.

27 S. A. Seyedmehdi, H. Zhang and J. Zhu, Appl. Surf. Sci., 2012, 258, 2972-2976.

28 D. Valade, F. Boschet and B. Ameduri, Macromolecules, 2009, 42, 7689-7700.

29 D. H. Li and M. Y. Liao, Mater. Rep., 2018, 32, 1730-1736.

30 R. Souzy, B. Ameduri, S. V. Ahsen, H. Willner and G. A. Arguello, J. Fluorine Chem., 2003, 123, 85-93.

31 A. Taguet, L. Sauguet, B. Ameduri and B. Boutevin, J. Fluorine Chem., 2007, 128, 619-630.

32 Z. Y. Yang, J. Org. Chem., 2003, 68, 5419-5421.

33 Y. Cheburkov and G. G. I. Moore, J. Fluorine Chem., 2003, 123, 227-231.

34 M. Pianca, P. Bonardelli, M. Tat, G. Cirillo and G. Moggi, Polymer, 1987, 28, 224-230.

35 M. Pianca, E. Barchiesi, G. Esposto and S. Radice, J. Fluorine Chem., 1999, 95, 71-84.

36 D. H. Li and M. Y. Liao, J. Fluorine Chem., 2017, 201, 55-67.

37 D. H. Li and M. Y. Liao, Polym. Degrad. Stab., 2018, 152, 116125.

38 S. Lin, Z. Y. Li, G. Luo and Y. Y. Chen, Chem. Ind. Eng. Prog., 2014, 33, 1276-1284.

39 A. J. Li, B. Feng and Q. C. Liu, Chin. J. Org. Chem., 2011, 31, 106-109.

40 G. J. Ross, J. F. Watts, M. P. Hill and P. Morrissey, Polymer, 2001, 42, 403-413.

41 J. H. Wei, X. Zhang, J. J. Qiu and L. Brandon, J. Polym. Sci., Part B: Polym. Phys., 2015, 53, 1691-1700.

42 D. H. Li and M. Y. Liao, Key Eng. Mater., 2017, 753, 93-98.

43 R. Souzy, B. Boutevin and B. Ameduri, Macromolecules, 2012, 45, 3145-3160.

44 A. Taguet, B. Ameduri and B. Boutevin, J. Polym. Sci., Part A: Polym. Chem., 2010, 44, 1855-1868. 
45 W. Posthumus, A. J. Derksen, J. A. M. van den Goorbergh and L. C. j. Hesselmas, Prog. Org. Coat., 2007, 58, 231-236.

46 N. Li, F. L. Zeng, Y. Wang, D. Z. Qu, W. B. Hu, Y. G. Luan, S. Dong, J. J. Zhang and Y. P. Bai, RSC Adv., 2017, 7, 30970-30978.
47 V. A. Ganesh, A. S. Nair, H. K Raut, T. T. Y. Tan, C. B. He, S. Ramakrishna and J. W. XU, J. Mater. Chem., 2012, 22, 18479-18485. 